\title{
The role of nuclear factor kappa B in periodontal diseases
}

\begin{abstract}
Periodontal (gum) diseases are inflammatory conditions caused by microbial dental biofilm. Chronic periodontitis is the most common form of the periodontal diseases result in loss of connective tissue attachment and supporting bone that may eventually result in loss of teeth. Nuclear factor kappa B $(\mathrm{NF}-\mathrm{kB})$ is a key regulator during inflammatory process involving the gingiva and alveolar bone of teeth. In this paper, we explain the role of NF-kB in the destructive process of teeth supporting tissues.
\end{abstract}

Keywords: periodontal diseases, NF-kb, gingiva, alveolar bone
Volume 6 Issue 3 - 2017

\author{
Luay Thanoon Younis, Mohamed Ibrahim Abu \\ Hassan \\ Department of Dentistry, University Technology Mara, Malaysia
}

Correspondence: Luay Thanoon Younis, Department of Dentistry, University Technology Mara, 47000 Sungai Buloh, Malaysia, Tel 603-61266632, Fax 603-61266103,

Email drluay@salam.uitm.edu.my

Received: October 16, 2016 | Published: February 13, 2017

\section{Introduction}

Severe periodontitis and caries incidence are increasing since two decades, ${ }^{1}$ and they are most prevalent diseases globally; where the oral conditions all ranked among the top 100 detailed causes of DALYs (disability-adjusted life-years) metric. Dental biofilm causes periodontal diseases and dental caries, affecting wide range human being and negatively affecting the quality of life (QOL) of the middleaged and older populations..$^{2-5}$ Denitrification is a process of nitrate reduction performed by facultatively anaerobic or microaerophilic organisms, but aerobic denitrification also occurs. ${ }^{6}$ Denitrification results in the formation of dinitrogen $\left(\mathrm{N}_{2}\right)$ from nitrate $\left(\mathrm{NO}_{3}\right)$ via nitrite $\left(\mathrm{NO}_{2}\right)$, nitric oxide $(\mathrm{NO})$ and nitrous oxide $\left(\mathrm{N}_{2} \mathrm{O}\right)$ intermediates. In the oral cavity, nitrate reduction is conducted by nitrate reducing bacteria which are residing dental biofilm on the teeth surfaces and surrounding gum. ${ }^{7}$ Nitrate from dietary sources is absorbed by the intestine and then re-absorbed from the bloodstream to be secreted into the oral cavity as a component of saliva. ${ }^{8}$ Nitrate-reducing bacteria in the dental biofilm reduce salivary nitrate to nitrite, ${ }^{6-11}$ which is further reduced to nitric oxide (NO) by nitrite reducing bacteria. ${ }^{12,13}$ Nitrate secretion in saliva would enhance the survival and growth of bacteria that possess the ability to respire nitrate. Hence, this creates a symbiotic relationship between the host and microbiota; the host providing environment and nutrients in return for nitrite production. ${ }^{6}$

\section{Denitrification effect on the progression of periodontal disease}

Periodontitis is an inflammatory disease resulting in the destruction of the supporting structures of the teeth (the periodontal ligament and the alveolar bone). It results in the formation of pockets between soft tissue of the gingiva and the tooth, can eventually cause tooth loss. ${ }^{14}$ Nitrogen oxides are the denitrification important products aggravating the damage of tooth supporting tissues during periodontitis. ${ }^{15}$ The amount Nitrogen oxides accumulated in the dental biofilm depends on the amount of nitrate in the food consumed. Nitric oxide oxidation would be another source for nitrogen oxides production in saliva. ${ }^{16}$ In case the plaque $\mathrm{pH}$ level remains low for ling time, this would lead to the accumulation of high percentage of nitrogen oxide in dental biofilm. If the byproducts scavenging process is delayed or suppressed, the nitrogen oxides diffuse into the surrounding gum tissues that would aggravate nitrogen oxide-induced damage to the gingival tissues. ${ }^{7}$ Previous studies proposed that over production of nitric oxide (NO) was implicated in the pathogenesis of periodontal disease. ${ }^{17,18} \mathrm{NO}$, at normal concentrations, is a messenger molecule organizes functions of immune system cells that are part of the inflammation. ${ }^{19}$ Lipopolysaccharides of the plaque bacteria can stimulate production of proinflammatory cytokines, which induce the immune cells to release high amount of NO. Subsequently, neutrophils would be induced to produce matrix metalloproteinases which causes further damage to the tooth surrounding tissues. ${ }^{20}$ Using selective inducible nitric oxide synthase inhibitor or scavenger was shown to be protective against the progression of alveolar bone loss. Furthermore, subgingival local delivery of NO inhibitors might be useful in the treatment of periodontal tissue inflammation, whereas systemic NO inhibitor delivery was shown to decrease bone resorption in an animal model of periodontitis. ${ }^{17}$

\section{Denitrification effect on dental caries formation}

Salivary nitrate reduction by the oral bacteria contributes to the major nitrite exposure in the human body. ${ }^{21}$ In the oral cavity, salivary nitrate will be utilized by bacteria that are capable of rapidly reducing nitrate to nitrite as part of their respiration. Mature dental biofilm is relatively thick and gelatinous which limits the diffusion of oxygen to deeper layers. Therefore, the microbes that survive in the deeper parts of the biofilm are facultative anaerobes. This would be the reason why nitrogen oxides are significantly higher in poor oral hygiene individuals than those with good oral hygiene who have thinner dental biofilm. ${ }^{22}$ Many anaerobic facultative bacteria synthesize nitrate reductase in low oxygen tension, ${ }^{9-24}$ hence, reduction can take place in the thick biofilm or deep tongue crypts. ${ }^{23}$ In thick cariogenic plaque, the low $\mathrm{pH}$ level allows the production of acidified nitrite. It was reported that $\mathrm{pH}$ below 7 would promote the conversion of $L$-arginine to $\mathrm{NO}$ and its compounds. ${ }^{25} \mathrm{NO}$ is one of the byproducts and it is recognized for its antibacterial effect that inhibit the acidogenic bacteria which are 
responsible for caries formation. ${ }^{22,26}$ Nitric oxide antibacterial effects are thought to include DNA modifications and interactions with other reactive species; for example, reaction with superoxide produces the highly reactive molecule peroxynitrite. ${ }^{27}$ Therefore, nitrate recycling and the availability of large amounts of nitrite in the oral cavity would result in bacteriostatic and possibly bacteriocidal effects which subsequently limit the survival of acidogenic bacteria and decrease caries formation. ${ }^{11-26}$

\section{Conclusion}

Human dental biofilm host many types of bacteria of which the nitrate reducing bacteria. These bacteria are utilizing the salivary nitrate for their respiration. Salivary nitrate is a reservoir from which a variety of nitrogen oxides are formed, most notably nitric oxide. Denitrification would have a dual effect either detrimental, by aggravating the damage of tooth supporting structure; or, beneficial by relatively limiting the dental caries formation.

\section{Funding}

None.

\section{Acknowledgments}

None.

\section{Conflicts of interest}

The authors declare that there is no conflict of interest.

\section{References}

1. Marcenes W, Kassebaum NJ, Bernabé E, et al. Global burden of oral conditions in 1990-2010: a systematic analysis. J Dent Res. 2013;92(7):592-597.

2. Selwitz RH, Ismail AI, Pitts NB. Dental caries. Lancet. 2007;369(9555):5159 .

3. Pihlstrom BL, Michalowicz BS, Johnson NW. Periodontal diseases. Lancet. 2005;366(9499):1809-1820.

4. O'Dowd LK, Durham J, McCracken GI, et al. Patients' experiences of the impact of periodontal disease. J Clin Periodontol. 2010;37(4):334-339.

5. Preshaw PM, Alba AL, Herrera D, et al. Periodontitis and diabetes: a twoway relationship. Diabetologia. 2012;55(1):21-31.

6. Doel JJ, Benjamin N, Hector MP, et al. Evaluation of bacterial nitrate reduction in the human oral cavity. Eur J Oral Sci. 2005; 113(1):14-19.

7. Takahama U, Hirota S. Nitrogen dioxide-dependent oxidation of uric acid in the human oral cavity under acidic conditions: implications for its occurrence in acidic dental plaque. Chem Res Toxicol. 2010;23(6):10671075 .

8. Speigelhalder B, Eisenbrand G, Preussman R. Influence of dietary nitrate on nitrite content of human saliva. Possible relevance to in vivo formation of N-nitroso compounds. Food Cosmet Toxicol. 1976;14(6):545-548.
9. Zetterquist W, Pedroletti C, Lundberg JO, et al. Salivary contribution to exhaled nitric oxide. Eur Respir J. 1999;13(2):327-333.

10. Pannala AS, Mani AR, Spencer JPE, et al. The effect of dietary nitrate on salivary, plasma and urinary nitrate metabolism in humans. Free Radic Biol Med. 2003;34(5):576-584.

11. Doel JJ, Hector MP, Amirtham CV, et al. Protective effect of salivary nitrate and microbial nitrate reductase activity against caries. Eur J Oral Sci. 2004;112(5):424-428

12. Palmerini CA, Palombari R, Perito S, et al. NO synthesis in human saliva. Free Radicl Res. 2003;37(1):29-31.

13. Takahama U, Hirota S, Oniki T. Production of nitric oxide-derived reactive nitrogen species in human oral cavity and their scavenging by salivary redox components. Free Radic Res. 2005;39(7):737-745.

14. Socransky SS, Haffajee AD. Dental biofilms: difficult therapeutic targets. Periodontol. 2002;28:12-55.

15. Lohinai Z, Stachlewitz R, Virág L, et al. Evidence for reactive nitrogen species formation in the gingivomucosal tissue. J Dent Res. 2001;80(2):470-475.

16. Aurer A, Aleksic' J, Ivic' Kardum M, et al. Nitric oxide synthesis is decreased in periodontitis. J Clin Periodontol. 2001;28(6): 565-568.

17. Lohinai Z, Benedek P, Feher E, et al. Protective effects of mercaptoethylguanidine, a selective inhibitor of inducible nitric oxide synthase, in ligature-induced periodontitis in the rat. Br J Pharmacol. 1998;123(3):353-360.

18. Lohinai Z, Szab6 C.Role of nitric oxide in periodontal tissues in health and disease [review]. Med Sci Monit. 1998;4:1089-1095.

19. Bogdan C. Nitric oxide and the immune response. Nat Immunol. 2001;2(10):907-916.

20. Ugar-Cankal D, Ozmeric N. A multifaceted molecule, nitric oxide in oral and periodontal diseases. Clin Chim Acta. 2006;366(1-2):90-100.

21. Tannenbaum SR, Sinskey AJ, Weisman M, et al. Nitrite in human saliva: Its possible relationship to nitrosamine formation. $J$ Natl Cancer Inst. 1974;53(1):79-84.

22. Bayindir, YZ, Polat MF, Seven N (2005) Nitirc oxide concentrations in saliva and dental plaque in relation to caries experience and oral hygiene. Caries Res 39(2): 130-133.

23. Li H, DuncanC, Townend J, Killham K, et al.Nitrate-reducing acteria on rat tongues. Appl Environ Microbiol. 1997;63(3):924-930.

24. Forman D, Al Dabbagh S, Doll R. Nitrates, nitrites and gastric cancer in Great Britain. Nature. 1985;313(6004):620-625.

25. Carossa S, Pera P, Doglio P, et al. Oral nitric oxide during plaque deposition. Eur J Clin Invest. 2001;31(10):876-879.

26. Silva Mendez LS, Allaker RP, Hardie JM, et al. Antimicrobial effect of acidified nitrite on cariogenic bacteria. Oral Microbiol Immunol. 1999;14(6):391-392.

27. Fang FC. Mechanisms of nitric oxide-related antimicrobial activity. J Clin Invest. 1997;99(12):2818-2825. 